\title{
Multivariate Analysis for Yield and Its Component Traits in Experimental Maize Hybrids
}

\author{
Ramesh Kumar ${ }^{1}$, G. K. Chikkappa ${ }^{1}$, S. B. Singh ${ }^{2}$, Ganapati Mukri ${ }^{3}$ J. Kaul ${ }^{3}$, A. K. Das ${ }^{1}$, D. Sravani ${ }^{4}$, D. S. Olakh ${ }^{1}$, \\ \& D. Bhatia ${ }^{5}$ \\ ${ }^{1}$ ICAR-Indian Institute of Maize Research, PAU Campus, Ludhiana, Punjab, India \\ ${ }^{2}$ Regional Maize Research and Seed Production Centre, Begusarai, Bihar, India \\ ${ }^{3}$ ICAR-Indian Agricultural Research Institute, Pusa Campus, New Delhi, India \\ ${ }^{4}$ Professor Jaishankar Telangana State Agriculture University, ARS, Karimnagar, Telangana State, India \\ ${ }^{5}$ Punjab Agriculture University, Ludhiana, Punjab, India \\ Correspondence: J. Kaul, ICAR-Indian Agricultural Research Institute, Pusa Campus, New Delhi 110012, India. \\ E-mail: kauljyoti1@yahoo.co.in
}

Received: December 2, 2016

Accepted: January 21, $2017 \quad$ Online Published: February 15, 2017

doi:10.5539/jas.v9n3p219

URL: http://dx.doi.org/10.5539/jas.v9n3p219

\begin{abstract}
Crop yields of major cereal including maize are not increasing at the targeted growth rates to feed the rising demands stemming from increase in the human population. To increase maize grain yield, there should be continuous improvement of cultures which are actively utilized by the plant breeders. Variability in germplasm is always the key to improvement and to assess the extent of variation is never ending process in a plant breeding program. Out of several methods available for assessing the variability, multivariate analysis is one of the most important and widely used methods. In the present study, 27 hybrids (including three checks) were evaluated for yield and yield contributing traits at three different locations during rabi 2013-14. Analysis of variance revealed significant variations among hybrids for all the traits. Based on Principal Component Analysis, $76.81 \%$ of the total variance in the data was accounted for by first four principal components (PC). Cluster analysis based on PC grouped the 27 hybrids into two major groups named as A and B. The group A further contained three sub-groups named as $A_{1}, A_{2}$, and $A_{3}$ with two hybrids falling in each group. Similarly group $B$ contained four subgroups classified as $B_{1}$ to $B_{4}$ with 2, 7, 5 and 7 hybrids falling in each subgroup respectively. The hybrids falling in two major groups contained more diversity than those falling in subgroups within a group. Selection of hybrids from the different groups would facilitate exploiting significant heterosis. Therefore, multivariate analysis including Principal component analysis followed by cluster analysis could be a reliable approach for assessing the extent of variability on in the germplasm and making its use in a suitable direction.
\end{abstract}

Keywords: Zea mays, multivariate analysis and principal component analysis, cluster analysis

\section{Introduction}

Maize (Zea mays L.) is one of the most commonly cultivated crops worldwide and is known as queen of cereals because of its highest genetic yield potential. It is among the most versatile crops having wider adaptability under varied agro-climatic conditions. Globally, it is cultivated in temperate, tropical and sub-tropical regions covering an area of nearly $160 \mathrm{~m}$ ha with the production of $817 \mathrm{mt}$ and productivity of $5.12 \mathrm{t} / \mathrm{ha}$. The United States of America (USA) is the largest producer of maize contributing nearly $43 \%$ of the total world production. The average productivity of hybrids in USA is $10.34 \mathrm{t} / \mathrm{ha}$, which is double than the global average (Maize Summit, 2015-2016). In Asia, maize is emerging as one of the most important crops in China, Bangladesh, India, Thailand, and Pakistan etc, with former leading the production scenario (FAO, 2014-2015).

In India, maize is the third most important food crops after rice and wheat with area coverage of 9.2 mha and production of $24.17 \mathrm{mt}$ (Anonymous, 2014-2015). Being predominantly grown in kharif season which covers $80 \%$ of the total area, maize has turned-out as a potential winter crop as well. It contributes nearly $9 \%$ to the national food basket and more than Rs. 100 billion to the agricultural GDP at current prices apart from the generating employment to over 100 million man-days at the farm and downstream agricultural and industrial sectors (Anonymous, 2016). In addition to staple food for humans and quality feed for animals, maize serves as a 
basic raw material as an ingredient to thousands of industrial products that includes starch, oil, protein, alcoholic beverages, food sweeteners, pharmaceutical, cosmetic, film, textile, gum, package and paper industries etc (Dass et al., 2009).

The entire maize growing area in India has been divided into five major zones. According to the zonal requirements and climatic situations, all the maturity groups (short, intermediate and long) are being cultivated. The right choice of maize genotypes for a given region is considered to be crucial for obtaining high grain yield (Ali et al., 2013). Single cross hybrids being highly productive are known to fetch better remuneration to the farmers. In India, only one-third of maize area is under hybrids, rest of the area is covered by OPVs and land races, as against the developed countries especially, USA, Germany etc., where $100 \%$ area is under hybrids with longer maturity duration. The average annual productivity of $2.56 \mathrm{t} / \mathrm{ha}$ is therefore far low than world average productivity. Hence there is a need to develop high yielding, genetically diverse and stable hybrids which can perform better under varying production conditions. Moreover, it has been estimated that by 2020 , the demand for maize in developing countries is expected to exceed 500 million tons and will surpass the rice and wheat demand (Pingali \& Heisey, 2001). The deployment of genetically diverse maize hybrids is expected to provide the capacity to meet changing environments and market requirements.

In order to understand the genetic diversity, breeders need to acquire prior knowledge of the appropriate methods to study the variability among the available germplasm (Mohammadi \& Prasanna, 2003). In fact several methods have been developed to estimate and understand the genetic diversity. Among these a multivariate analysis facilitates graphic display of the underlying latent factors as well as interface between individual samples and variables (Nielsen \& Munck, 2003). Principal component analysis (PCA) has been widely used in plant sciences for a reduction of variables and grouping of genotypes. This would help in identifying broad based genetically distinct genotype for different agro-morphological parameters.

\section{Materials and Methods}

A set of 100 inbred lines was evaluated for per se performance over a four diverse environments. Based on the mean yield performance and its maturity 2, 5 and 20 lines were selected in early, medium and late maturing category respectively. Lines having high productivity $(>3.00 \mathrm{t} / \mathrm{ha})$ with medium cob placement were grouped as female parent and lines with long main tassel branch, sparse tassel with few tassel branches were grouped as male parent. Using these selected inbred lines, total of 24 experimental hybrids (2-parent combinations) combinations were attempted during Kharif, 2012 at Delhi, as shown in Table 1. 
Table 1. Details of crosses along with pedigree of inbred lines used in generating new hybrid combinations

\begin{tabular}{|c|c|c|c|c|c|}
\hline S.No. & Inbred lines & Pedigree of inbred Lines & Maturity duration & S. No. & Hybrids \\
\hline 1 & DML 1089 & HY10R-N 10235-319 & Medium & 1 & DML 1089 X HKI-1105 \\
\hline 2 & DML 1100 & Swan & Late & 2 & DML 1100 X HKI-1105 \\
\hline 3 & DML 1112 & JCY2-7 & Late & 3 & DML 1112 X HKI-1105 \\
\hline 4 & DML 1113 & JCY2-7 & Late & 4 & DML 1113 X HKI-1105 \\
\hline 5 & DML 1113 & JCY2-7 & Late & 5 & DML 1113 X HKI-1128 \\
\hline 6 & DML 1114 & JCY2-7 & Late & 6 & DML 1114X HKI-1105 \\
\hline 7 & DML 1114 & JCY2-7 & Late & 7 & DML 1114 X HKI-1128 \\
\hline 8 & DML 1115 & MRCHY 4840-4 & Medium & 8 & DML 1115 X HKI-1128 \\
\hline 9 & DML 1115 & MRCHY 4840-4 & Medium & 9 & DML 1115 X HKI-1105 \\
\hline 10 & DML 1116 & MRCHY4852-1 & Late & 10 & DML 1116 X HKI-1128 \\
\hline 11 & DML 1116 & MRCHY4852-1 & Late & 11 & DML 1116 X HKI-1105 \\
\hline 12 & DML 1121 & MRCHY4864 & Medium & 12 & DML 1121 X HKI-1105 \\
\hline 13 & DML 1132 & JCY2-7 & Late & 13 & DML 1132 X HKI-488 \\
\hline 14 & DML 1133 & JCY2-7 & Late & 14 & DML 1133 X HKI-488 \\
\hline 15 & DML 1324 & VL-1018681 & Medium & 15 & DML 1324 X HKI-488 \\
\hline 16 & DML 1356 & MRCHY 4738-4 & Late & 16 & DML 1356 X HKI-488 \\
\hline 17 & DML 1356 & MRCHY 4738-4 & Late & 17 & DML 1356 X HKI-1105 \\
\hline 18 & DML 1415 & MRCHY 4840-2 & Late & 18 & DML 1415 X HKI-1128 \\
\hline 19 & DML 1417 & MRCHY 4840-2 & Late & 19 & DML 1417 X HKI-1105 \\
\hline 20 & DML 1441 & MRCHY 5158-2 & Late & 20 & DML 1441 X HKI-1105 \\
\hline 21 & DML 1441 & MRCHY 5158-2 & Late & 21 & DML 1441 X HKI-1128 \\
\hline 22 & DML 1442 & MRCHY 5158-2-1 & Late & 22 & DML 1442 X HKI-1128 \\
\hline 23 & DML 1591 & PEHM-2 & Early & 23 & DML 1591 X HKI-1128 \\
\hline 24 & DML 1591 & PEHM-2 & Early & 24 & DML 1591 X HKI-1105 \\
\hline 25 & HKI 1128 & Unknown source & Medium & 25 & Bio 9637 (Check) \\
\hline 26 & HKI 1105 & Cargill 633 & Medium & 26 & Buland (LM $11 \times$ LM 12) (Check) \\
\hline 27 & HKI 488 & Cargil 501 & Early & 27 & Seed tech 2324 (Check) \\
\hline
\end{tabular}

And the same were evaluated, along with checks, during Rabi 2013-14 at three locations i.e. Begusarai (Bihar), MPUA\&T, Udaipur and PJSTSAU (formerly ANGRAU) Agricultural Research Station, Karimnagar (Telangana) in Randomized Block Design with three replications. The crop was raised at a spacing of $60 \times 20 \mathrm{~cm}$ in single row of 3 meter length. The recommended packages of practices of the region were followed to raise the crop under stress-free production system. The observations were recorded on yield and yield contributing traits viz., days to tasseling $(50 \%)$, days to silking $(50 \%)$, plant height $(\mathrm{cm})$, ear height $(\mathrm{cm})$, cob length $(\mathrm{cm})$, cob girth $(\mathrm{cm})$, kernel rows per cob, number of kernels per row, shelling percentage and grain yield $(\mathrm{kg} / \mathrm{plot})$. The morpho-phenological and yield data were analyzed using SAS software version 9.3.

\section{Results and Discussion}

Analysis of variance revealed the significant variability present in the material under study for some traits (Table 2). For yield, the range was recorded with highest yield ( $99.85 \mathrm{q} / \mathrm{ha})$ and lowest yield $(40.52 \mathrm{q} / \mathrm{ha})$ depicting the significant variability in the material for grain yield. Similarly for other traits namely plant height $(105.00-192.00 \mathrm{~cm})$, ear height $(60.0-115.0 \mathrm{~cm})$, cob length $(13.50-23.0 \mathrm{~cm})$, cob girth $(14.0-18.0 \mathrm{~cm})$, kernel rows (12.0-18.0), number of kernel/rows (23.0-42.0) and shelling percentage (72.22-93.90), the range of variation was recorded. Khorasani, Mostafavi, Zandipour, and Heidarian (2011), also observed similar variability in maize hybrids. 
Table 2. Mean, range and mean sum of squares values for different traits

\begin{tabular}{llllll}
\hline S. No. & Traits & Mean Values \pm SD & Minimum & Maximum & Mean Sum of Squares \\
\hline 1 & Days to tasseling $(50 \%)$ & $110.09 \pm 4.14$ & 103.00 & 120.00 & $7.42^{*}$ \\
2 & Days to silking $(50 \%)$ & $112.05 \pm 4.70$ & 103.00 & 122.00 & $12.74^{* *}$ \\
3 & Plant height $(\mathrm{cm})$ & $164.50 \pm 19.66$ & 105.00 & 192.00 & $718.26^{* *}$ \\
4 & Ear height $(\mathrm{cm})$ & $88.07 \pm 13.53$ & 60.00 & 115.00 & $254.71^{* *}$ \\
5 & Cob length $(\mathrm{cm})$ & $18.86 \pm 2.25$ & 13.50 & 23.00 & 5.05 \\
6 & Cob girth $(\mathrm{cm})$ & $15.73 \pm 0.95$ & 14.00 & 18.00 & 0.94 \\
7 & Kernel rows & $14.66 \pm 1.78$ & 12.00 & 18.00 & 2.76 \\
8 & No. of kernel/row & $31.94 \pm 4.16$ & 23.00 & 42.00 & 19.85 \\
9 & Shelling\% & $83.51 \pm 4.13$ & 72.22 & 93.90 & 12.09 \\
10 & Grain Yield (q/ha) & $72.25 \pm 13.45$ & 40.52 & 99.85 & $314.57^{* *}$ \\
\hline
\end{tabular}

Note. ${ }^{*}, * *$ indicates significance at $\mathrm{p}<0.05$ and $\mathrm{p}<0.01$ respectively.

In the present investigation principal component analysis (PCA) has been widely used in plant sciences for reduction of variables and grouping of genotypes. The Principal Component Scores were used for clustering maize genotypes into subgroups because a few principal components contained all the information of the original variables (Syafii et al., 2015). In the present investigation, first four principal components (PC) had accounted for $76.81 \%$ of the total variance in the data (Table 3). The first Principal Component adsorbed and accounted for maximum proportion of the variability in the set of all PCs and remaining ones for progressively lesser and lesser amount of variation. However the $5^{\text {th }} \mathrm{PC}$ accounted for $9.03 \%$ of total variation. This meant that first $4-5$ traits (days to tasseling (50\%) days to silking (50\%), plant height, ear height and cob length) contributed significantly to the observed variation and these traits are representing the maximum variability as also revealed analysis of variation. This also indicates that the type of observed variation can be used for further improvement. Similar observations were also reported by Daudo and Olakojo (2007), while working on striga tolerant maize lines.

Table 3. Eigen values and percent variation accounted for the first 10 principal components

\begin{tabular}{llll}
\hline Factor & Eigen value & Variance $(\%)$ & Cumulative Variance (\%) \\
\hline 1 & 2.71839 & 28.23 & 28.23 \\
2 & 2.13479 & 22.17 & 50.4 \\
3 & 1.57153 & 16.32 & 66.72 \\
4 & 0.97181 & 10.09 & 76.81 \\
5 & 0.86944 & 9.03 & 85.84 \\
6 & 0.53028 & 5.51 & 91.35 \\
7 & 0.37742 & 3.92 & 95.27 \\
8 & 0.24028 & 2.5 & 97.77 \\
9 & 0.15779 & 1.64 & 99.41 \\
10 & 0.0579 & 0.6 & 99.46 \\
\hline
\end{tabular}

The analysis without rotation of axes failed to load all the variables signifying that it could not offer much information regarding the idea of correlation between the variables. Factor loadings of different variables which were obtained by using PCA are presented in Table 4. The first principal factor (PF 1) enabled loading of days to tasseling $(50 \%)$ days to silking (50\%), cob girth and kernel rows indicating the importance of these traits for PC 1. Plant height, ear-height, shelling percentage and grain weight per plot were important for PC 2 whereas cob length and kernel per row were important for PC 3 and plant height, shelling percentage and grain weight were most important for PC 4. By using these four PC's it was observed that these four PCs controls the total variation for all yield traits. It is depicted from Figure 1 also that, days to tasseling (50\%) days to silking (50\%), cob girth and kernel rows had positive correlation with PC 1 and plant height and ear height had positive correlation with PC 2 and among these also. ANOVA also revealed the significant variability for the characters contributing to PC 1 and PC 2. Mustafa, Farooq, Hassan, Bibi, and Mahmood (2015), also found similar type of results and 
concluded that selection of the traits having higher eigen values would definitely contribute towards diversity of the material used. Mustafa, Aslam, Hassan, and Farooq (2014) and Jolliffe (2002), also emphasized on using diverse genotypes based on component traits.

Table 4. Factor loadings (Eigen vectors) of different traits with respect to different principal components in selected maize hybrids

\begin{tabular}{llllll}
\hline S. No. & Traits & PF 1 & PF 2 & PF 3 & PF 4 \\
\hline 1 & Days to tasselling (50\%) & $\mathbf{0 . 5 2 2 3 4 3}$ & -0.126991 & 0.178205 & 0.100532 \\
2 & Days to Silking (50\%) & $\mathbf{0 . 5 5 1 5 8 5}$ & -0.090273 & 0.094989 & 0.081643 \\
3 & Plant height & -0.020527 & $\mathbf{0 . 4 9 0 6 1 8}$ & -0.312818 & $\mathbf{0 . 4 7 0 6 2 0}$ \\
4 & Ear height & 0.089917 & $\mathbf{0 . 5 6 5 5 1 9}$ & -0.194437 & 0.282812 \\
5 & Cob length & -0.195196 & 0.220101 & $\mathbf{0 . 5 8 8 8 1 7}$ & 0.098825 \\
6 & Cob girth & $\mathbf{0 . 4 7 5 9 3 6}$ & 0.058529 & -0.212653 & -0.068699 \\
7 & Kernel rows & $\mathbf{0 . 3 6 2 6 9 8}$ & 0.077705 & 0.001203 & -0.104628 \\
8 & Kernels per row & 0.114801 & 0.210794 & $\mathbf{0 . 6 3 7 4 8 7}$ & 0.240046 \\
9 & Shelling percentage & -0.038188 & $\mathbf{- 0 . 4 2 4 3 8 5}$ & 0.032220 & $\mathbf{0 . 6 3 1 7 0 2}$ \\
10 & Grain wt/plot & -0.060008 & $\mathbf{- 0 . 3 6 4 3 6 3}$ & -0.155576 & $\mathbf{0 . 4 4 6 8 3 3}$ \\
\hline
\end{tabular}

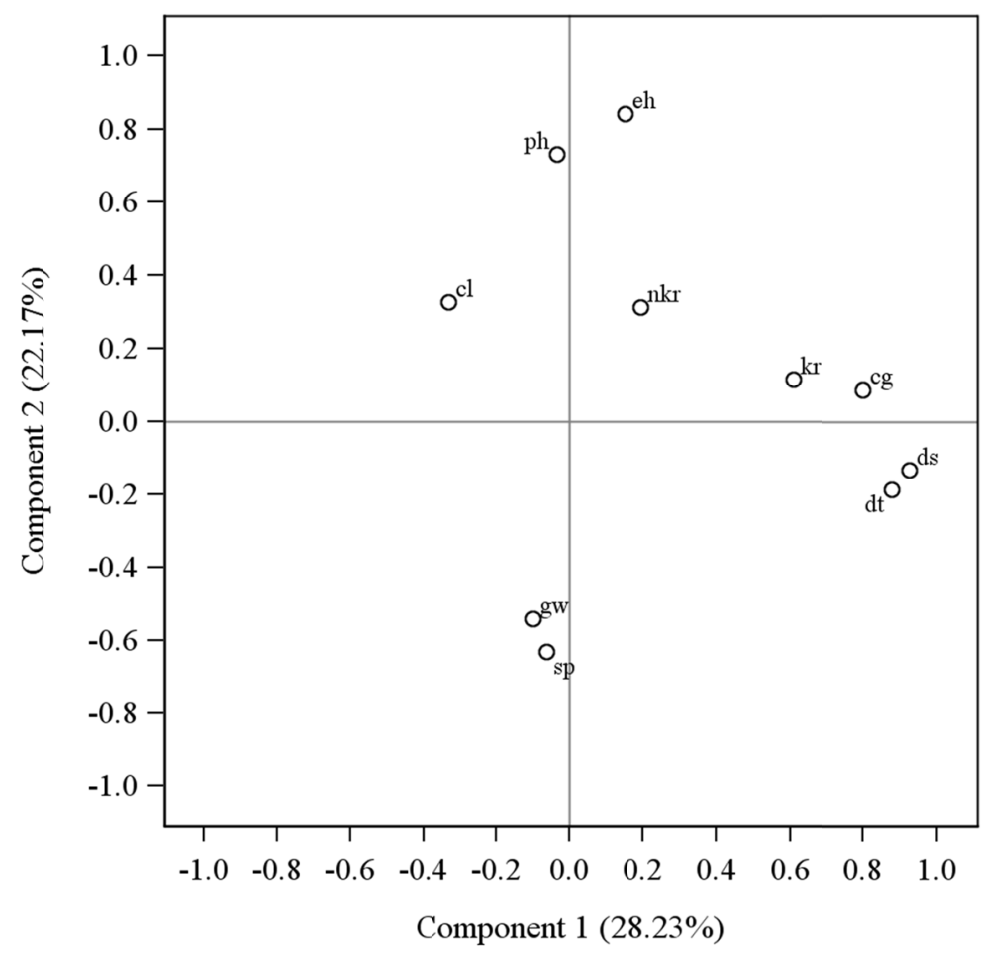

Figure 1. Graphical representation of different morphological traits through PCA

These four variables in PCA's were also used for Hierarchical cluster analysis for grouping of the genotypes. Based on cluster analysis 27 hybrids were grouped in two major groups A and B (Figure 2). These two major groups were again categorized into sub-groups. The group $\mathrm{A}$ is further divided into three sub-groups viz., $\mathrm{A}_{1}, \mathrm{~A}_{2}$, and $A_{3}$. Hybrids 23 and 26 fell in sub group $A_{1}$; hybrid 13 and 25 fell in $A_{2}$ and 5 and 16 fell in sub group $A_{3}$. Similarly group $\mathrm{B}$ was classified in to $\mathrm{B}_{1}(1,2), \mathrm{B}_{2}(12,14,15,18,20,21,27), \mathrm{B}_{3}(3,9,17,19,24)$ and $\mathrm{B}_{4}(4,6$, $7,8,10,11,22)$. 


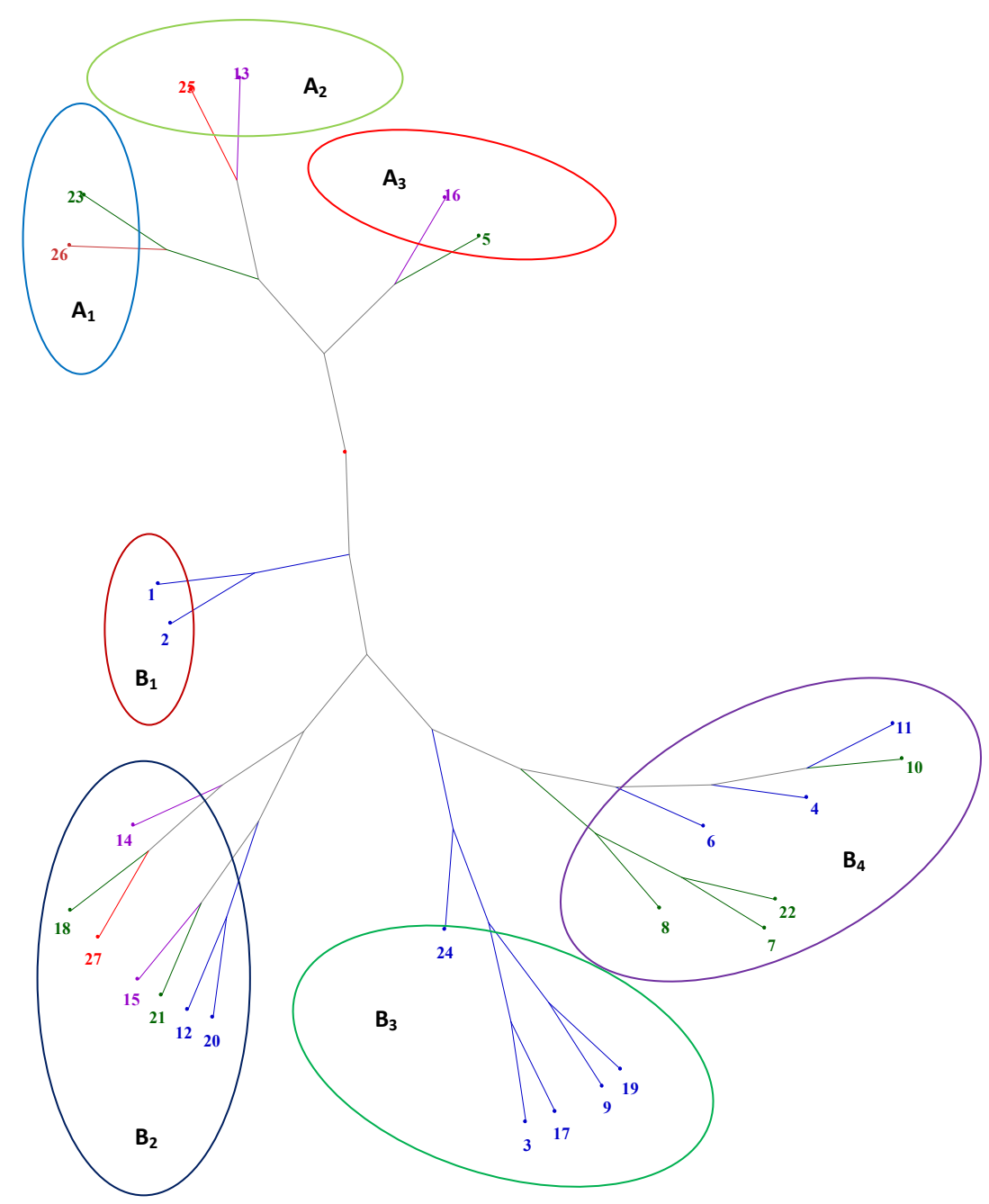

Figure 2. Grouping of hybrids based on morphological data using Hierarchical cluster analysis

In the group A, hybrids 5 and 16 emerged as distinct hybrids, compared to the checks, as these form separate cluster. Both the male and female parents used to develop these hybrids also have unique pedigree $i e$., females were derived from JCY2-1 and MRCHY 4738-4 and males used were HKI 1128 and HKI 488 respectively for the development of hybrids 5 and 16. Subgroups $A_{3}, B_{3}$, and $B_{4}$ did not grouped with checks, indicating that these hybrids might have some distinct phenotypic character compared to checks. Average yield performance of $A_{3}, B_{3}$, and $B_{4}$ groups surpassed the yielding ability of checks used. This may be due to the uncommon origin and complementary effect of inbred lines utilized to derive these hybrids. On the other hand genotypes grouped under sub groups $A_{1}, A_{2}$ and $B_{2}$ tend to move along with hybrids having yielding ability equal or lesser than checks. This may be attributed due to the commonality in the ancestral (Table 1 and Figure 2) background of the inbred lines utilized in the development of hybrids. The classification of subgroups also found to depend on the common tester involved in the development of cross combinations. Azad, Biswas, Alam, and Alam (2012) had observed that the crosses involving parents belonging to the maximum divergent clusters were expected to manifest maximum heterosis and also wide variability in the genetic architecture.

\section{Conclusion}

In the present study careful selection of inbred lines with different back ground and wide genetic distance assisted the hybrids to out-yield the checks performance. This was again supported by the cluster analysis and pattern of falling genotypes belonging to different clusters. Thus, we can use the parents of the cross combinations which are appearing in different cluster for exploiting maximum heterosis. Principal component analysis also supports the breeder to select diverse genotypes by its indirect selection through yield attributing characters. 


\section{Reference}

Anonymous. (2014-2015). Advance Estimate of APY. Retrieved from http://agricoop.nic.in/statistics/advanceestimate-apy-english

Anonymous. (2016). Farmer's Portal. Retrieved from http://farmer.gov.in/FarmerHome.aspx\#

Azad, M. A. K., Biswas, B. K., Alam, N., \& Alam, S. S. (2012). Genetic Diversity in Maize (Zea mays L.) Inbred Lines. The Agriculturists, 10(1), 64-70. https://doi.org/10.3329/agric.v10i1.11066

Ali, Q., Ahsan, M., Ali, F., et al. (2013). Heritability, heterosis and heterobeltiosis studies for morphological traits of maize (Zea mays L.) seedlings. Advanced Life Science, 1(1), 52-63.

Dass, S., Kaul, J., Manivannan, S. A., \& Chikkappa, G. K. (2009). Single cross hybrid maize - A viable solution in the changing climate scenario. Indian J. Genet., 69(4), 331-334.

Daudo, T. O., \& Olajoko, S. A. (2007). Principle component analysis of Striga-Tolerant maize varieties. Research Journal of Agronomy, 1(2), 94-98.

FAO. (2014-2015). FAO Statistics. Retrieved from http://www.fao.org/3/a-i4691e.pdf

Jolliffe, I. T. (2002). Principal Component Analysis (2nd ed.). Springer-Verlag, New York, USA.

Khorasani, S. R., Mostafavi, K., Zandipour, E., \& Heidarian, A. (2011). Multivariate analysis of agronomic traits of new corn hybrids (Zea mays L.). Int. J. Agri. Sci., 1(6), 314-322.

Mohammadi, S. A., \& Prasanna, B. M. (2003). Analysis of Genetic Diversity in Crop Plants-Salient Statistical Tools and Considerations. Crop Sci., 43, 1235-1248. https://doi.org/10.2135/cropsci2003.1235

Mustafa, H. S. B., Farooq, J., Hassan, E. U., Bibi, T., \& Mahmood, T. (2015). Cluster and Principle component analysis of maize accessions under normal and water stress conditions. Journal of Agricultural Sciences, 60(1), 33-48.

Mustafa, H. S. B., Aslam, M., Hassan, E. U., \& Farooq, J. (2014). Genetic variability and path coefficient in maize (Zea mays L.). Journal of Agricultural Sciences, 9(1), 37-43. https://doi.org/10.4038/jas.v9i1.6352

Nielsen, J. P., \& Munck, L. (2003). Evaluation of malting barley quality using exploratory data analysis. I. Extraction of information from micro-malting data of spring and winter barley. J. Cereal Sci., 38(2), 173-180. https://doi.org/10.1016/s0733-5210(03)00023-7

Pingali, P., \& Heisey, P. W. (2001). Cereal-Crop Productivity in Developing Countries. In J. M. Alston, P. G. Parday, \& M. J. Taylor (Eds.), Agricultural Science Policy: Changing Global Agendas. The John Hopkins University Press, Baltimore and London.

Syafii, M., Cartika, I., \& Ruswandi, D. (2015). Multivariate analysis of genetic diversity among some maize genotypes under Maize-Albizia cropping systems in Indonesia. Asian J. Crop Sci., 7(4), 244-255. https://doi.org/10.3923/ajcs.2015.244.255

\section{Copyrights}

Copyright for this article is retained by the author(s), with first publication rights granted to the journal.

This is an open-access article distributed under the terms and conditions of the Creative Commons Attribution license (http://creativecommons.org/licenses/by/4.0/). 